\title{
Study on the Connotation of Sports in the Process of Urbanization
}

\author{
Wang Qin, Yan Chaobing \\ Institute of Physical Education of Jiujiang University, JiangXi Province, China \\ Yan8085@126.com
}

\begin{abstract}
Along with our country urbanization speed, sport has gradually attracted the attention of everyone in the study of the relationship between. For further in-depth understanding and objective understanding of the relationship between urbanization and sports, using literature data and logical analysis method based on a comprehensive interpretation of the connotation of urbanization, by analyzing the urbanization process in the community sports, rural sports, traditional sports reform and explore the new object, process and evaluation of the connotation of sports study shows: the urbanization, and sports between mutual promotion relationship is not a simple, but in different stages of development of towns show different characteristics.
\end{abstract}

Index Terms - Urbanization; Sports; Connotation

\section{Introduction}

As an important sign of modernization, urbanization can promote the local infrastructure and the construction of public service system, the expansion of domestic demand, is expected to become China's new economic growth point. In recent years, with the increase of sports development level and social status improved, I border many scholars began to sports development issues in the process of urbanization, related research is increasing, many researchers believe that the urbanization construction and the development of sports to promote each other, mutual influence. As a modern way of life, sports industry and urbanization have the intrinsic relation. However, how the specific relationship between the two? Interactive effects of how to treat both? Based on the understanding of the connotation of the urbanization, the research community has been discussed, in the face of the relationship between the two from the logic layer. Understanding the relationship between China's urbanization and the development of sports people generally and objectively in order to provide the valuable thoughts.

\section{The Connotation of Urbanization}

According to the characteristics of the regional division of the social administration in China, used the "urbanization" and "city", rarely used "urbanization". The connotation of urbanization, domestic scholars tend to comprehensive interpretation, such as: urbanization is a process of social change, is a systems engineering, including human, financial, governance, road and other core elements, means that the re combination of social elements of the re allocation and social relations. The urbanization is the process of urban population, urban scale expanding, the rural population flowing to the town and city civilization to the countryside and the mode of production and life of the people caused by the diffusion of change and value variance. The urbanization is the industrialization, on-agricultural industries continue to urban concentration, the historical process which the rural population to non-agricultural industries and to cities and towns, rural areas to urban transformation, increase in the number of towns and continues to expand the scale of production, life style and the towns urban civilization continue to spread to the rural communication. From different scholars explanation can be found in the basic elements, namely: urbanization includes adjusting the transfer, industrial structure of population and lifestyle changes, with the aid of appropriate discipline background to some factor that is foreign scholars analysis of urbanization way. Such as: demography, urbanization is the transfer of rural population to non-agricultural population of the pursuit, and the increasing proportion of urban population. From the point of view of economics, the urbanization is the process to a planned economy to a market economy, the rural economy to city economy transformation. From a sociological point of view, urbanization is the city social life style, influence on rural lifestyle coverage and substitution process.

\section{The Relationship between Urbanization and Several Sports Terminology}

\section{A. Urbanization and rural sports or sports for farmers}

From the scope and object region, transition of urbanization and rural construction and farmer identity directly related, it also shows that both have the intrinsic relation. Research thinks: "urbanization is an important driving force for the development of rural sports; rural sports development can promote rural urbanization." "Provides the effective carrier of the further development of the rural 'urbanization' for the rural sports, the peasants' Citizenization of farmers' sports development has laid a good foundation." In addition, there are studies the urbanization correspond to the new rural construction, think "new rural sports construction, not only to think about the peasants' sports demand from the 'people' meaning, should also be from the 'people' significance to find the value of physical education on farmers. In practice, although the village as the key of the development of rural sports new has been left, but the key position in the development of rural sports in villages and towns is not over." From the point of view on the expression of words, are able to withstand repeated scrutiny, are ideal explanation on the urbanization and rural or farmer sports interaction. However, 
from the analysis of the logical level and practice level, the idea of fuzzy relations are sports in the process of urbanization and rural sports, and not really explain the relationship between the two. In addition, affecting the development of rural sports to urbanization depends on the physical level, the level of development and the social sports on sports cognition level. While the long-term influence of two structures in urban and rural areas, the development of rural sports is far behind the theory should reach the level of. In this sense, its impact on the urbanization is very limited.

\section{B. Urbanization and community sports}

"In accordance with the division of community comprehensive standard, the community can be divided into the city and rural communities." "Urban community is a form of existence between city and countryside, geographically and rural community closer, in the way of life and more to the city as the standard." Attributes from the towns and communities, both of them have the elements of the same and external characteristic. From the logic level, urban sports should be included in the community sports, they can share in the research purpose, research object, research content and research methods etc. It is precisely because of this between urban sports and community sports special relationship, repeated study makes the fair for the urbanization process and the development of sports phenomenon. Such as: "the current community sports Township rural is the most common problem is lack of money, three: missing, missing, or lack of personnel, lack of funds, lack of facilities." this problem and similar studies of over generalization, the lack of targeted, not only can not explain the special conditions of the sports development in the process of urbanization from the theory, also reduced the real value of. In fact, the urbanization is a long process, not a state of stagnation or already realized the fact. Many researchers seem to have positive impact on urbanization may give sports brings, as already realized the fact. This is the self understanding of the most probably it did not actually happen.

\section{Urbanization and the folk sports and traditional sports}

In a sense, urbanization means the way of life and production modernization, the development of folk sports and traditional sports will influence can not be ignored. From the quantity and quality of existing research, this kind of research is the most popular in researchers' attention. Such as: "urbanization has an important driving role of Chinese folk sports development, the prosperity and development of folk sports culture can promote urbanization." "Urbanization with the arrival of the inheritance and development of folk sports are facing opportunities and challenges, and find a new combination of folk sports and social development is a prerequisite for the development of folk sports." However, "the relationship between urbanization and the development of the folk sports of our country is dialectical," also had a difficult to avoid the damage of folk sports or traditional sports development, the "existence of national traditional sports cultural space and the soil gradually destroyed and give up." And effect of "China folk sports in the urbanization of the existence of the project, regional development is not balanced, form, and function change reality." In fact, exist in the development of the folk sports and traditional sports in question is a common phenomenon in all things the development may face, and urbanization is not directly or inevitable connection, be attributed to the effect of urbanization and no real significance.

\section{Comparison of Urbanization and Sports}

From the connotation of urbanization and sports, this seems to be not comparable. But the development process and the evaluation standard of the service object, have the intrinsic relation. At the same time, through the comparison of the two, contribute to a more comprehensive and in-depth understanding of both the.

\section{A. Comparison of urbanization and sports service object}

From the connotation of urbanization, is a gradual process of industrial agglomeration and population urbanization, which mainly concerns and benefit farmers. Sport is regarded as a kind of cultural activities to promote the healthy development of the human body and mind, also can be understood as a process of the development of physical and mental health education, the service object and the group to benefit all the people. From the related object size, urbanization and sports is the relationship between farmers and the people, the whole and the parts from the characteristics of the object; also, the farmer sports development situation directly affect the development level of people in sports, especially like the current our country such a large population base and a high proportion of the national population of farmers. In addition, sports development level depends largely on the level of economic development, while the latter is often considered the key index to evaluate the level of urbanization. Therefore, we can say, the urbanization level directly affects the development level of sports. However, in the different time, the different influence on the latter degree.

\section{B. Comparison of the development process of urbanization and sports}

"Urbanization is a long process, to fully understand the long-term sex and complexity of urbanization. According to China's East, West, in different circumstances, step by step, distinction, indefinite administrative goals, not to make it rigidly uniform. Don't jump on the bandwagon of grass-roots government, do not spoil things by excessive enthusiasm, not to blindly administrative movement." in fact, because of the influence of the fundamental realities of the country and local government awareness, urbanization of China has evolved into a "movement". Is only this kind of political, direct objective fitness effect and is thought to be of different sports. However, from the process of development, sports development has followed or are following similar trajectory is forward. To some extent, as one of the important content of modern lifestyle, the development of sports is always accompanied by the process of urbanization. Even can say, the development of 
sports and the urbanization of China is basically consistent with the context, is the early construction of the excessive pursuit of material level, and then to make up for lack of spirit, and enhance the development of logical connotation to extension follow after. Only the pursuit of many-storied buildings on urbanization, city shape change; and the development of sports venues and facilities on the pursuit of physical, physicochemical methods with.

\section{Comparison of urbanization and sports evaluation criteria}

Urbanization involving land, household, education, social security, medical care and a series of institutional, policy issues, it can be said that the "urbanization is a set of public policy," and not easy to statistics, the proportion of the urban population, urban construction scale and level of economic development with the as evaluation criteria. Similarly, index of the development level of sports also can not simply rely on the venue facilities, sports population increase or sports industry level, but including the construction of stadiums, event organization, fitness guide, optimize the structure of sports industry and so on. From the pursuit of the goal to achieve results, both are closely connected with the development level of economy, politics, culture, both of which rely on social reform and social organizational system and its synchronous development. In other words, both are economic development, a product of social development, and can not simply think is a process for promoting or planning implementation. Of course, this does not mean we should give up the efforts and let it free or blind development; on the contrary, we should proceed from reality in different regions of China, adhere to the overall and balanced development principle, scientific planning and guidance, promote the steady and healthy development.

\section{The Relation between Sports and Urbanization}

In general, the relation between sports and urbanization can be analysed from the physical to the status and the function in the urbanization process. "Judging from the current situation seriously restricted the urbanization system bottleneck of many. Is the land system, the household registration management system and city administration system? In order to realize the strategy target Town must change the institutional epoch." From the urbanization to overcome and solve problems, establish and sports public service design sports public service system supply can only be regarded as a secondary position problem; from the practical problems to deal with in order of priority, the public service of sports right shall be based on the farmers to enjoy the public housing, treatment health care, social security, education etc.. Of course, this does not mean that the sport is not important, but not as many researchers say "so important"; at least in the early stage of urbanization development, the status of secondary.

In addition, the sports to urbanization, is a complex and dynamic process, specifically, is along with the change of the urbanization level and the change of. According to the city American geographer Ray M - Northman's point of view, there are three stages in the development of urbanization development, and each stage of urbanization showed different characteristics. From the urbanization speed, in the early and late city population growth is very slow; in the middle stage of urbanization, the city population increased faster, $50 \%$ can be a breakthrough in the decades up to $70 \%$, this stage is also known as a stage of rapid development of urbanization. Overall, the interaction between sports influence on urbanization or two also show similar features. In the early of urbanization, many problems need to be solved; the basic social system corresponding imperfect, physical impact on urbanization is weak. In the middle stage of urbanization, with the identity more peasants' citizenization of transformation and adaptation, and perfect the corresponding system and service, sports as a modern way of life of people, the daily life into and affect the public, the urbanization has a positive and direct effect. Urbanization later, along with the advancing of city population increase, the social civilization and people living concepts change, in addition, due to the cumulative impact of modern lifestyle defects, urbanization rate; at the same time, because of the diversification to improve sports level and life style, influence of sports on urbanization will slow down however, the more important to people's daily life.

According to statistic, to 2011, the rate of Chinese city of $51.3 \%$. In accordance with the USA City geographer Ray M - Northman's point of view, China has entered a period of accelerated development of urbanization. This also means: in this stage, the sports development level of urbanization have a positive and significant role in promoting. Taking this opportunity, the sports management departments should be scientific planning, reasonable allocation of sports resources, so as to ensure the sports play a positive role in the process of urbanization in china. Of course, the intervention on external can improve the urbanization and the development of sports level, but the rate of increase is limited; change the corresponding to physical form and implement equipment, the influence of the mind is more profound and lasting. In view of this, the integrated and coordinated principles play an important role to ensure effective sports in the process of urbanization.

\section{Conclusion}

In fact, the urbanization is an old topic, as the world's first complete urbanization country, England in eighteenth Century has started at the beginning of the urbanization construction. At the same time, Britain is also the socialization of sports high country. In our country, with the pace of modernization, urbanization has already started quietly, never stop. But in recent years by the government as a strategic target put forward, at the same time pay attention to. Similarly, in our country, and to study the relationship between urbanization and sports is not a new problem, from the beginning of the founding of the socialist movement to reform and opening up until today, sports, social research about rural sports under different background transformation research, research on non material cultural heritage protection from the 
perspective of folk or traditional sports and so on, despite the different view or background research, but the logic and the properties of the same. There is a certain inherent and extrinsic similarity development process and evaluation object, urbanization and sports in their respective concerns. To some extent, the development of urbanization and sports are all material internalized unity and the appearance of spirit. At the same time, levels of development between urbanization level and sports should not be considered a simple linear relationship between the different stages of development, but in the towns have different characteristics. In view of the current our co. In view of the current our country has entered a period of accelerated development of urbanization, the sports management should make full use of this opportunity, the overall plan, reasonable planning, give full play to the role of sports in the process of positive effects on the cities and at the same time, the promotion of sports is more comprehensive and healthy development.

\section{References}

[1] Lang Yongchun. Li Gang, Li Weiyan. "Thinking on the evolution of Chinese folk sports in the process of Urbanization" Journal of Beijing Sport University, pp.165-167, February 2008.

[2] Zheng Guohua. "Urbanization and the development of folk sports in China -- A case study of Jiangxi province "Xiao Zhen" folk sports" Journal of Wuhan Sports Institute, pp.1-8, June 2007.

[3] Xu Yong. "Deepening understanding" Title in seven agricultural and forestry work communication to rural towns, pp.48-50, April 2013.

[4] Xiang Chun Ling. "Adhere to the overall and balanced" Realism, modern management in the process of urbanization, pp.25-27, February 2013.

[5] [Zhang Zhanbin. "New urbanization strategy significance and problems in the reform of" Journal of National School of Administration, pp.4854, January 2013. 